\title{
Dramatic variations in emergent wetland area in China's largest freshwater lake, Poyang Lake
}

Xuefei Mei ${ }^{\mathrm{a}}$, Zhijun Dai ${ }^{\mathrm{a},{ }^{*}}$, Sergio Fagherazzi ${ }^{\mathrm{b}}$, Jiyu Chen $^{\mathrm{a}}$

${ }^{a}$ State Key Lab of Estuarine and Coastal Research, East China Normal University, Shanghai, China

${ }^{\mathrm{b}}$ Department of Earth and Environment, Boston University, USA

*Corresponding author

Zhijun Dai

State Key Lab of Estuarine and Coastal Research,

East China Normal University,

Shanghai,

China

Email: zjdai@sklec.ecnu.edu.cn; zhijun_dai@hotmail.com

Tel: +86 2162233458 ;

Fax: +862162546441

Abstract Freshwater wetlands are important ecosystems experiencing rapid degradation around the world. As much as $64 \%$ of world's wetland area has been lost since 1900; the situation is even more serious in Asia, where land reclamation and anthropogenic modifications of rivers are increasing the rate of wetland disappearance. In this study, we provide a first complete estimation of daily Emergent Wetland Area (EWA) in Poyang Lake, China's largest freshwater lake, from 1955 to 2012. A wavelet analysis indicates a strong periodicity in the monthly EWA time series with two oscillations having a period of 12 and 60-72 months, respectively. A dramatic increase in mean annual EWA is detected since 2003, when the Three Gorges Dam (TGD) was completed, mainly due to the seasonal drying of $1078 \mathrm{~km}^{2}$ of wetlands in October. It is found that the timing of wetland emergence during the dry season has been anticipated of one month, from November to October, since the establishment of TGD. It is argued that a significant increase in wetland exposure and an observable shift in the seasonal timing of flooding and drying will seriously degrade the wetland system and threaten the endangered migratory birds that inhabit it unless effective countermeasures are implemented.

Keywords: Variations in lake water level; Emergent wetland area; Poyang Lake; Three Gorges Dam (TGD) 


\section{Introduction}

Wetlands are delicate environments at the interface between aquatic and terrestrial systems (Cowardin et al., 1979). Covering $6 \%$ of the world's land surface, wetlands are highly productive ecosystems, serving as important habitats for a variety of wildlife (Erwin, 2009). Globally, wetlands are disappearing at an alarming rate. As much as $64 \%$ of wetland area has been lost worldwide since 1900, representing the worst decline among all ecosystems on Earth (Davidson, 2014).

Long-term wetland dynamics are poorly understood despite their vital importance (Maltby, 1990). Both on-site observations and modeling are challenging due to limited accessibility caused by the dense vegetation canopy. In recent years, remote sensing has enabled the monitoring of wetland extension. For example, Prigent et al. (2001) quantified the seasonal extent of global wetlands with a suit of satellite observations at $0.25^{\circ}$ spatial resolution. The U.S. Fish and Wildlife Service used remote sensing techniques, including aerial and satellite imagery, to determine the location, extent, status, and trend of wetlands in the United States for the past 30 years (Tiner, 1996; Klemas, 2011).

Digital elevation models (DEMs) can also be used as an accurate and fast tool to characterize large portions of the landscape, and have considerable applications in wetland studies (Todd et al., 2010). For instance, Harvey et al. (2009) determined the total surface water inundation of a vegetated floodplain by comparing water levels with a ground DEM. Töyrä and Pietroniro (2005) documented the utility of DEM for the categorization of flooded and non-flooded areas in a northern wetland in Alberta, Canada. Ordoyne and Friedl (2008) predicted surface inundation in the Everglades, Florida, using a DEM in conjunction with satellite data.

As the largest freshwater lake in China, Poyang Lake $\left(28.37^{\circ}-29.75^{\circ} \mathrm{N}\right.$ and $115.78^{\circ}$ $-116.75^{\circ} \mathrm{E}$ ) is located in the middle of the Changjiang (Yangtze) River basin, and it is naturally connected to the Changjiang River at Hukou (Fig. 1). Poyang Lake is characterized by dramatic seasonal fluctuations in water level that favor the development of about $3000 \mathrm{~km}^{2}$ of freshwater wetlands in the high-water season (Zhang et al., 2014). Poyang Lake wetlands, as one of the world's six major wetland systems, serve as a unique and important ecosystem. Sedges (Carex spp.) are the main aquatic vegetation, dominating areas at an elevation between $14.2 \mathrm{~m}$ and $16 \mathrm{~m}$ above the Wusong datum (Sang, 2014). From October to March, Poyang Lake wetlands are a critical habitat for migratory birds, including the highly endangered Siberian crane, 
Grus leucogeranus (Tullos, 2009). Recently, the natural fluctuations of water level in Poyang Lake have been changing dramatically, inducing an early seasonal drying of a large portion of the wetland area accompanied by longer periods of low water levels. As a result, some of the native Carex communities risk to be replaced by upland vegetation, seriously affecting the ecology of both lake and wetlands, and putting the wintering water birds - in danger (Feng et al., 2013). As the unusual low water levels along the middle-lower Yangtze River coincide with the filling of the world's largest hydroelectric dam, the Three Gorges Dam (TGD), a discussion about whether TGD should be blamed for those drought events was brought forward (Lai et al., 2014; Dai et al., 2012; Qiu, 2011). Although some studies have been conducted on how the TGD affects the Poyang Lake's ecosystem (Guo et al., 2012; Zhang et al., 2012; Feng et al., 2013), few of them examined variations in Emergent Wetland Area (EWA). Investigating the time-evolution of EWA has a vital significance to other natural wetlands around the world and provides important information that can be used for the conservation and management of Poyang Lake.

The main objectives of this research are: 1) to determine the link between EWA and lake water level; 2) to investigate the long-term variations of EWA in Poyang Lake with statistical analyses; and 3) to identify the driving forces affecting the EWA of Poyang Lake.

\section{Data and Methods}

\subsection{Data}

To determine the area of the lake flooded for a given water elevation, we reconstruct the lake bathymetry by combining two sets of data collected respectively in 1998 and 2010 (1:10000, or 5 m resolution). The bathymetries were obtained from the Hydrological Bureau of the Jiangxi Province. We further use the following datasets: (1) daily water level records at Xingzi station from 1955 to 2012; (2) daily river discharges at Yichang and Datong station for the period 1955-2012. These data were provided by the Changjiang Water Resources Commission. Moreover, daily precipitation data over the Poyang Lake catchment, covering a time period from 1960 to 2012, were made available by the National Climatic Centre of the Chinese Meteorological Administration.

\subsection{Method}


A series of analyses were conducted to examine the statistical characteristics of the EWA time series in Poyang Lake. Specifically, Morlet wavelet analysis was applied to both normalized and filtered monthly EWA to detect all time-scales of variation. Global wavelet spectrum, a measure of wavelet variance, was used to detect the contributions of different time periods to the EWA signal. Determination of long-term trends and points of abrupt change were based on the results of the Mann-Kendall test and the Standard Normal Homogeneity Test (SNHT), respectively.

\section{Morlet wavelet transform}

Wavelet transform aims to decompose a localized time-frequency phenomena in a certain number of wavelets (Torrence and Compo, 1998). The continuous wavelet transform of signal $\mathrm{x}(\mathrm{t})$ can be expressed by:

$$
W(\mathrm{a}, \mathrm{b})=<x(\mathrm{t}), \varphi_{a, b}(\mathrm{t})>=\int_{-\infty}^{+\infty} x(\mathrm{t}) \varphi_{a, b}^{*}(\mathrm{t}) d t=\frac{1}{\sqrt{a}} \int_{-\infty}^{+\infty} x(\mathrm{t}) \varphi^{*}\left(\frac{t-b}{a}\right) d t \quad \mathrm{a}, \mathrm{b} \in \mathrm{R}, \mathrm{a} \neq 0
$$

where $a$ and $t$ are scale and time parameter, $\varphi(\mathrm{t})$ and $\varphi^{*}(\mathrm{t})$ represent the wavelet coefficient and the complex conjugate of the wavelet coefficient, respectively.

The Morlet wavelet is defined as the product of a complex exponential wave and a Gaussian envelope:

$$
\varphi(\mathrm{t})=e^{i w_{0} t} e^{-\frac{1}{2} t^{2}}
$$

where $w_{0}$ is the central frequency of the mother wavelet.

\section{Global wavelet spectrum}

Global wavelet spectrum, which is defined as the averaged variance contained in the wavelet coefficients of scale $a$ in the time domain, can be expressed as (Hao et al., 2012):

$$
\operatorname{Var}(\mathrm{a})=\int_{-\infty}^{+\infty}|W(\mathrm{a}, \mathrm{b})|^{2} d b
$$

The wavelet variance can be used to detect the contributions of the principal periods at different time scales.

\section{Mann-Kendall test}

The Mann-Kendall test determines trend in a data set based on the statistic $S$ (Kendall, 1975):

$$
S=\sum_{i=1}^{n-1} \sum_{j=i+1}^{n} \operatorname{sgn}\left(x_{j}-x_{i}\right)
$$


Where $x_{i}$ and $x_{j}$ are sequential data series with $i=1,2,3, \ldots n-1$ and $j=i+1, i+2, i+3, \ldots n$, $n$ is the sample size, and

$$
\operatorname{sgn}(\theta)=\left\{\begin{array}{cc}
+1 & \theta>0 \\
0 & 0 \\
-1 & \theta<0
\end{array}\right.
$$

Mann (1945) stated that, when $n \geq 8$, the statistics $S$ follows an approximately normal distribution with the mean and variance given by:

$$
\mathrm{E}(\mathrm{S})=0 ; \quad \operatorname{Var}(\mathrm{S})=\frac{n(n-1)(2 n+5)-\sum_{i=1}^{n} t_{i}\left(t_{i}-1\right)\left(2 t_{i}+5\right)}{18}
$$

where $t_{i}$ is the number of ties of extent $i$. The standardized test statistic $Z_{M K}$ is given by

$$
Z_{M K}=\left\{\begin{array}{cl}
\frac{S-1}{\sqrt{\operatorname{Var}(S)}} & S>0 \\
0 & S=0 \\
\frac{S+1}{\sqrt{\operatorname{Var}(S)}} & S<0
\end{array}\right.
$$

It is assumed that, under the null hypothesis, there is no trend; however, the null hypothesis will be rejected when the absolute value of $Z_{M K}$ is above 1.96 at significant level of 0.05 .

\section{Standard normal homogeneity test}

The SNHT identifies the possible differences between the mean of the first $a$ years of the record and the mean of the last $n$ - $a$ years based on the statistic $T_{0}$, which is defined as (Alexandersson and Moberg, 1997):

$$
T_{0}=\max _{1 \leq a<n} T_{(a)}=\max _{1 \leq a<n}\left(a \bar{z}_{1}^{2}+(n-a) \bar{z}_{2}^{2}\right), a=1,2, \ldots, n
$$

where

$$
\bar{z}_{1}=\frac{1}{a} \sum_{i=1}^{a} \frac{\left(Y_{i}-\bar{Y}\right)}{s} ; \bar{z}_{2}=\frac{1}{n-a} \sum_{i=a+1}^{n} \frac{\left(Y_{i}-\bar{Y}\right)}{s}
$$

$\bar{Y}$ denotes the mean value of the data set, $s$ is the standard deviation of the sample, and $n$ is the length of the data set. 
When $T_{(a)}$ has a maximum $T_{0}$ at year $a=A$, a significant shift occurs if $T_{0}$ is above the critical value at a given significance level. The critical value is dependent on the sample size (Jarusková, 1994).

\section{Mapping of emergent wetland area}

DEMs of the Poyang Lake were obtained from 1:10000 bathymetric maps and were analyzed within a Geographic Information System to predict inundation area. All spatial data were referred to the 1985 National Elevation datum. A Triangulated Irregular Network (TIN) was used to generate attribute data. The TIN was converted to a raster DEM using Kriging. Based on Poyang Lake's morphology, the surface area was extracted once every $0.5 \mathrm{~m}$ for water levels below $11 \mathrm{~m}$ or above $16 \mathrm{~m}$, and in intervals of $0.1 \mathrm{~m}$ for water levels between $11 \mathrm{~m}$ and $16 \mathrm{~m}$. The extracted surface area and associated water level were interpolated with Matlab. An eleven-degree polynomial yields the best correlation between surface area and corresponding water level.

The maximum inundated area of Poyang Lake is $3721 \mathrm{~km}^{2}$ when the water level reaches $23 \mathrm{~m}$. This inundated area is defined as Poyang Lake wetland (Andreoli et al., 2007). Accordingly, daily EWA is defined herein as the difference between the maximum inundated area and the instantaneous inundated area on each day (Fig. 2).

The relationship between EWA and real-time water level is given by:

$$
a=A-\sum_{i=1}^{m} p_{i} w^{m-i}
$$

where $A$ is the maximum inundated area of Poyang Lake; $\sum_{i=1}^{m} p_{i} w^{m-i}$ is the inundation area on each day that depends on the water level $w ; p_{i}$ are the polynomial coefficients (Table 1).

\section{Results}

\subsection{Relationship between water level and emergent wetland area}

In this study, Xingzi station is used to represent the hydrological regime of Poyang Lake (see also Zhang et al., 2014; Ye et al., 2014). The variation and linear trend in annual water level during 1960-2010 are shown in Fig. 3. The water level at Xingzi is stable until the mid-1980s, and then continuously increases until the end of the 1990s (Fig. 3). The water level starts declining in 2000, resulting in severe drought conditions. Overall, the annual water level during the study period presents a 
decadal-term declining trend at a rate of $0.06 \mathrm{~m}$, which coincides with the results of Ye et al. (2014), who indicated a slight decadal decreasing trend at a rate of $0.03 \mathrm{~m}$ over the same period. Specifically, the decadal mean lake level at Xingzi during the 1960s, 1970s, 1980s, 1990s, 2000s are 13.34, 13.23, 13.69, 13.88, and $12.76 \mathrm{~m}$, respectively. The decadal averaged water levels are almost identical to those reported in Zhang et al. (2014), who obtained 13.33, 13.22, 13.67, 13.87, and $12.74 \mathrm{~m}$ at the same station. Thus, our findings on water level variations agree well with previous results.

Poyang Lake has a shallow and uneven bathymetry with a natural slope from south to north (Fig. 1c). The EWA of Poyang Lake can be expressed as a function of maximum inundation area and water level. EWA is negatively correlated to water level, reaching high values during the dry season and decreasing as the water level increases (Fig. 1d). Changes in EWA are subtle near low $(<11 \mathrm{~m}$ by the Wusong datum) and high water (>16 $\mathrm{m}$ by the Wusong datum), while a dramatic decrease in EWA occurs when the water level ranges between 11 and $16 \mathrm{~m}$. An $11^{\text {th }}$ order polynomial fit is used to establish the relationship between EWA and water level at Xingzi $\left(\mathrm{R}^{2}=0.999\right.$ with $\left.p<0.001\right)$ (Fig. 1d), which is then used throughout the paper to compute variations in EWA.

\subsection{Periodicity of emergent wetland area}

The monthly EWA pattern is strongly seasonal with extensive exposed wetlands during the dry season and reduced extension during the wet season (Fig. 4a). As a whole, EWA in the wet season can reach an area of $3500 \mathrm{~km}^{2}$, which reduces to about $850 \mathrm{~km}^{2}$ during the dry season (Fig. 2). Decadal variations of monthly EWA are highlighted in Fig. 4b. To clearly identify the impacts of TGD on Poyang Lake hydrology, here the decades used in the analysis are set based on the construction year of the TGD (2003). A sudden increase in monthly EWA is detected in October after the beginning of the TGD operations. The mean annual EWA in Poyang Lake increases by $13 \%$ from $2169 \mathrm{~km}^{2}$ during 1955-2002 to $2456 \mathrm{~km}^{2}$ during 2003-2012 ( $t$-test, with $p<0.05$, Fig $4 \mathrm{c}$ ). Inter-annual variation in EWA indicates a less significant decrease in terms of coefficient of variation $\left(\mathrm{C}_{\mathrm{v}}\right)$, which diminishes from $59 \%$ to $51 \%$ ( $t$-test, $p<0.1$, Fig $4 \mathrm{~d}$ ). A lower $\mathrm{C}_{\mathrm{v}}$ indicates a smaller likelihood of fluctuations in lake storage from year to year.

The Morlet wavelet analysis identifies two types of quasi-periodic oscillations in the monthly EWA time series at a significant level of 0.05 (Fig. 5). We first normalize the monthly EWA time series by subtracting the mean value from the raw data and 
dividing the difference by the standard deviation. The normalized monthly EWA has a noticeable periodicity of 12 months over the period of 1955-2012, indicating the seasonal variation in EWA. We then filter the series, removing the low-amplitude peaks by summing over a subset of scales. The filtered time series has a periodicity of 60-72 months, implying long-term oscillations in EWA.

\subsection{Variation of daily emergent wetland area}

The time series of daily EWA in pre- and post-TGD periods are compared in terms of frequency distribution, by dividing the daily data into 11 intervals of EWA from $<600 \mathrm{~km}^{2}$ to $>3300 \mathrm{~km}^{2}$ with a bin size of $300 \mathrm{~km}^{2}$. The distributions, together with the cumulative distributions, are separately plotted for each month (Fig. 6).

No significant variation between the frequency distributions before and after the dam construction is observed in the first quarter (from January to March), when the EWA is mostly above $3300 \mathrm{~km}^{2}$ (Fig. 6a-c). A significant increase of EWA after the TGD construction is detected in April, when the percent of days with area above 3300 $\mathrm{km}^{2}$ rises from $12.3 \%$ in the pre-TGD period to $55.3 \%$ in the post-TGD period, suggesting an increase of $43 \%$. This rising tendency appears to be easing in the following two months (May and June). The percent of days with a EWA over 3300 $\mathrm{km}^{2}$ increases by $18 \%$ in May and $3 \%$ in June, respectively (Fig. 6d-f). In the third quarter, from July to September, the percent of days with EWA below $600 \mathrm{~km}^{2}$ experiences a significant decrease, while that with EWA between 600-900 $\mathrm{km}^{2}$ dramatically increases following the TGD infilling (Fig. 6g-i). In particular, the most frequent EWA in September shifts from below $600 \mathrm{~km}^{2}$ to $600-900 \mathrm{~km}^{2}$ after the TGD construction. In October and November, an increase in EWA appears again after the establishment of the TGD, while no significant difference between pre-TGD and post-TGD data is detected in December (Fig. 6j-1).

As a result, extensive wetland exposure during the dry season occurs earlier in the post-TGD period (Fig. 6j). EWA above $3300 \mathrm{~km}^{2}$ accounts for $38.1 \%$ in November under natural conditions before the dam construction, while a similar percentage of days with EWA above $3300 \mathrm{~km}^{2}$ is reached in October in the post-dam period (36.2\%, Fig. 6k).

\subsection{Variation of monthly emergent wetland area}

The monthly EWA series are examined for long-term trend detection. During the pre-TGD period from 1955 to 2002, monthly EWA in May and October appear to be slightly increasing in time, while monthly EWA in June are random without any trend. The remaining 8 months exhibit decreasing trends; among them, January, July and 
December show a statistically significant decrease in EWA across the years (Mann Kendall test with $\mathrm{p}<0.05$, Table 2). Inclusion of post-TGD data in the analysis reverses decreasing trends in September and November, with EWA increasing during these months. EWA is also increasing faster in May and October, while decreasing less in the remaining months. Moreover, the insignificant upward trend in October becomes significant (Mann-Kendall test with $\mathrm{p}<0.05$ ). A statistically significant change point was found around 2003 for April and October EWA time series, which coincide with the filling of the TGD reservoir (Table 2). Compared to the pre-TGD period, the average monthly EWA in April and October has increased by $575 \mathrm{~km}^{2}$ and $1078 \mathrm{~km}^{2}$, respectively.

\section{Discussion}

Potential variations in the water level of the Poyang Lake wetlands can be ascribed to climate change and human disturbances. Climate change could alter precipitation regimes and thus runoff. Human disturbances include the regulation of the Changjiang River by the TGD, water withdrawal for agricultural irrigation, hydraulic structures and sand mining in the Poyang Lake basin. Moreover, the temporal and spatial variation of Poyang Lake topography may also induce water level variations within the lake.

\subsection{Poyang Lake basin morphology}

Two sets of bathymetric data, taken in 1998 and 2010, were combined in this research to generate an integrated DEM for Poyang Lake. Possible changes in lake bathymetry in this period might have affected the relationship between EWA and water level. In view of this, we compare the central cross section of the lake (Fig. 1b) in 1998 and in 2010 (Fig. 7). As the figure demonstrates, no significant difference is observed during the 12-year period. Specifically, the mean elevation of the cross section was $11.02 \mathrm{~m}$ in 1998 and $10.98 \mathrm{~m}$ in 2010, indicating a slight decrease of 0.04 $\mathrm{m}(0.33 \%)$, which has limited influence on the EWA-water level relationship. Other researchers studied variations in bottom topography across Poyang Lake through quantification of erosion and deposition patterns between 1998 and 2010. These studies indicate that the lake's boundary and bathymetry have remained stable in the last two decades (Wu and Liu, 2015; Zhu et al., 2014).

The existence of depression areas within the lake may induce spatial variations of lake level (Kalff, 2002). When the water level in the lake drops, depressions may keep enclosed water bodies for a considerable time, which will not interact with the water 
in the lake. These isolated areas should be discarded when calculating the daily EWA. The bottom of Poyang Lake is smooth and flat in general (Hu et al., 2010). In spite of some small depressions, the mean relief amplitude of the lake bottom is $0.60 \mathrm{~m}$, with $96.7 \%$ of the area having a bottom amplitude smaller than $1.65 \mathrm{~m}$. The average surface roughness ratio is 1.00 , with $96.0 \%$ of the area having a roughness ratio smaller than 1.00 (Xu et al., 2014). This means that the entire Poyang Lake is hydrologically connected and differences in water level across the lake are minimal.

\subsection{Precipitation}

Poyang Lake experiences a seasonal rainfall pattern with intensive rain between April and July (Andreoli, et al., 2007). The monthly time series of basin precipitation during 1956-2012 is significantly correlated to that of EWA with $p<0.01$ (see Fig. 8).

Precipitation over the Poyang Lake basin affects the EWA in two ways: precipitation over the lake directly increases the lake water level; precipitation on the tributaries' watersheds increases the water inflow into the lake thus affecting the EWA. Monthly precipitation records over the lake indicate a significant decrease in April since 2003 with respect to the monthly precipitation in the period 1955-2003, resulting in an average reduction in April rainfall of $56.1 \mathrm{~mm}$ (Table 3). In addition, the water volume discharged in April by local streams into the lake decreased from $158.5 \times 10^{8} \mathrm{~m}^{3}$ during $1960-2002$ to $134.5 \times 10^{8} \mathrm{~m}^{3}$ during 2003-2012. These two phenomena significantly reduced the April water level in Poyang Lake in the post-TGD period. Moreover, water withdrawal for agricultural irrigation in early spring might have exacerbated the reduction in water level in April (Ye et al., 2013). As a result, around $575 \mathrm{~km}^{2}$ of additional wetland surface is exposed in this month. Although EWA in April displays an abrupt variation around 2003, the increase trend in EWA started in the 1990s, before the TGD operations. As Fig. 9 indicates, the decadal EWA in April presents significant fluctuation, with a minimum in the period 1983-1992. On the other hand, the decadal EWA in October shows a sudden increase in the 2000s, which coincides with the TGD impoundment. Therefore, a correlation between the EWA increase in April and the construction of the TGD is not supported by our data.

In October, the decrease of precipitation on the lake and the decrease in tributary inflow are $14.9 \mathrm{~mm}$ and $13.7 \times 10^{8} \mathrm{~m}^{3}$, respectively, which are much smaller than those experienced in April (Table 3). However, the increase in exposed wetland area in October is $1078 \mathrm{~km}^{2}$, almost double that of April. Therefore, other causes drive the extensive wetland exposure in October. 


\subsection{Human activities in Poyang Lake catchment}

The Poyang Lake catchment has been affected by intensive human activities, including the construction of hydraulic structures and sand mining. 9783 reservoirs with a total storage capacity of 29.3 billion $\mathrm{m}^{3}$ were present in the Poyang Lake basin in 2007. However, most of these reservoirs were built before the 1980s, and the total number of reservoirs in the catchment has remained stable since then (Fig. S1). These hydraulic structures induced sudden variation in the total volume of water in the lake in the 1980s (Fig. 4b). The operations of these artificial reservoirs are strictly regulated by the government so that they cannot cause significant changes in lake level. Therefore, hydraulic structures in the Poyang Lake catchment should not be linked to lake variations in recent decades.

Sand dredging in the Poyang Lake started in 2001 and was banned in 2008. In this period, the extraction rate of sand was around $236 \times 10^{6} \mathrm{~m}^{3} /$ year (de Leeuw et al., 2010), creating scars shaped like a moon or a dish (Fig. 10). In spite of high extraction rates, sand mining mainly occurred along the outflow channel of the Poyang Lake and only created local disturbance (Lai et al., 2014). When extrapolating the extracted sand over the $3000-\mathrm{km}^{2}$ lake surface, the effect of sand mining on bottom elevation is relatively limited and cannot fully explain the recent variations in lake level (Mei et al., 2015). Moreover, most of the scars are below the horizontal datum and the elevation of the water table, and were therefore immediately filled by underground water, thus seldom participating to surface water fluxes in the lake (Fig. 10). Therefore, sand extraction may not affect the EWA and the relationship between EWA and water level in the Poyang Lake.

\subsection{Effect of Three Gorges Dam operations}

Outflow from Poyang Lake to the Changjiang River is controlled by the difference between the lake and the river water levels. The TGD, currently the largest hydraulic structure in the world, affects the Poyang Lake wetland system in two fundamental ways: by trapping sediment and by regulating water discharge in the Changjiang River.

TGD stores a huge amount of sediment, changing the river carrying capacity, which leads to permanent channel erosion downstream the dam (Dai and Liu, 2013). Compared with the substantial channel incision occurred at Jiujiang after the construction of the TGD, the cross-section of the Poyang Lake's outlet at Hukou is basically stable (Mei et al., 2015). The mean difference in bottom elevation between the mainstream of the Changjiang River and Poyang Lake outlet increased by $1.03 \mathrm{~m}$ 
from 2007 to 2011, fundamentally altering the water discharge from the lake into the river. Moreover, TGD usually starts to impound water in late September, thus significantly modifying the downstream discharge. The monthly average discharge in October has reduced from $18182 \mathrm{~m}^{3} / \mathrm{s}$ to $12268 \mathrm{~m}^{3} / \mathrm{s}$ at Yichang since 2003 , when the TGD was established. Similarly, river discharge at Datong has decreased by 7531 $\mathrm{m}^{3} / \mathrm{s}$ from $32910 \mathrm{~m}^{3} / \mathrm{s}$ to $25378 \mathrm{~m}^{3} / \mathrm{s}$ in October because of the TGD operations (Table 4). The reduction in river flow has increased the difference in water level between the Changjiang River and the Poyang Lake, augmenting the water discharged by the lake in the river and thus enlarging the wetland exposed area. Therefore, TGD plays an important role in affecting Poyang Lake EWA in October and November. It should be mentioned that the discharge in April displays a different pattern with respect to October. Compared with the dramatic discharge decline in October, in April the discharge at Datong has only decreased by $2342 \mathrm{~m}^{3} / \mathrm{s}$ since 2003 , while the discharge at Yichang has even increased by $337 \mathrm{~m}^{3} / \mathrm{s}$ (Table 4). Therefore, the TGD is mildly affecting the discharge of the Changjiang River in April, resulting in a smaller difference between lake and river water level and a smaller EWA in Poyang Lake.

\subsection{Comparison of EWA variations in Dongting Lake and Poyang Lake}

Dongting Lake and Poyang Lake, China's two largest freshwater lakes, are both located along the central Changjiang river basin. The two lakes have suffered significant hydrological variations since the construction of the TGD (Chang et al., 2010; Mei et al., 2015). The wintertime growth rate of EWA in the East Dongting Lake has increased from $12.3 \mathrm{~km}^{2} /$ year to $14.1 \mathrm{~km}^{2} /$ year after the construction of the TGD, while the minimum EWA elevation has been reducing at a rate of $7.9 \mathrm{~cm} /$ year with respect to a decreasing rate of $3.1 \mathrm{~cm} /$ year for the period 1995-2003 (Xie et al., 2015). In the same period, Poyang Lake experienced similar hydrological trends. Following the establishment of the TGD, the EWA in winter has increased while the EWA minimum elevation has decreased. Specifically, the growth rate of EWA has increased from $5.01 \mathrm{~km}^{2} /$ year during 1995-2003 to $9.02 \mathrm{~km}^{2} /$ year during 2004-2011, while the reduction rate of EWA minimum elevation has changed from $1.78 \mathrm{~cm} / \mathrm{year}$ to $3.12 \mathrm{~cm} /$ year (Table 5).

It is worth noting that, although both Dongting Lake and Poyang Lake display a serious reduction in area after 2003, the way in which the two lakes are shrinking is different. Specifically, since the TGD was constructed, Dongting has suffered a drastic reduction in EWA minimum elevation rate, but a relatively minor growth in EWA as compared to Poyang Lake. These differences can be explained by the bathymetry of 
the two lakes: Dongting Lake has a maximum inundation area of $2623 \mathrm{~km}^{2}$ with a maximum depth of $30.8 \mathrm{~m}$ while Poyang Lake covers an area of $3289 \mathrm{~km}^{2}$ with a maximum depth of $21.71 \mathrm{~m}$ (Zhang et al., 2013). This means that a larger area of the Poyang Lake can become subaerial as the lake level declines. Accordingly, Poyang Lake is experiencing a smaller reduction in EWA minimum elevation while displaying a larger increase in EWA.

\subsection{Early exposure of wetland area in Poyang Lake}

Globally wetlands are rapidly declining. The United States experienced a net loss of $134 \mathrm{~km}^{2}$ of coastal wetlands from 1998 to 2004 (Dahl, 2006). Around $0.005 \mathrm{~km}^{2}$ of wetland area is disappearing or degrading every minute in Canada (Bond et al., 1992). In Asia, approximately $5000 \mathrm{~km}^{2}$ of wetland is lost annually (Zedler and Kercher, 2005). While extensive wetland area is disappearing throughout the world due to reclamation, the Poyang wetland system is undergoing degradation due to reduced water levels. From 1955 to 2002, the low water season in Poyang Lake started around the middle of November, when the water level at the Xingzi station approached $12 \mathrm{~m}$ and EWA approached $3150 \mathrm{~km}^{2}$ (Tan et al., 2013). Following the construction of the TGD, a large portion of the wetlands are already exposed in October, statistically affecting the EWA time series. The earlier start of the low water season combined to an increase of $1000 \mathrm{~km}^{2}$ of wetland exposure can be catastrophic for the lake ecosystem. Once the freshwater wetlands turn to mudflats, the substrates dries, with permanent loss of marsh vegetation. Prolonged periods without water may irrevocably compromise wetland's resilience and adaptability to water level variations, which can result in permanent degradation or disappearance. Moreover, early wetland dry-up facilitates the germination and expansion of invasive upland species, which can outcompete the native vegetation. It can be expected that the entire ecosystem will be damaged, including winter birds that feed on the native species.

\section{Conclusions}

As one of the world's six major freshwater wetlands, the Poyang Lake wetland system is of great regional and international value. Poyang Lake experienced a serious water level decline in recent years that increased the exposed (dry) portion of the wetlands. This study relates emergent wetland area to variable water levels in the lake using a high resolution DEM. We have investigated the long-term variations in exposed wetland area and ascertained the causes of these variations. In particular, we determined the role of the annual filling of the Three Gorges Dam (TGD) reservoir on 
the hydrology of Poyang Lake. The main conclusions are summarized below:

(1) The Emergent Wetland Area (EWA) displays a strong seasonal variability and a long-term oscillation with period of 60-72 months.

(2) Poyang Lake has experienced an increase in EWA in April and October since the establishment of the TGD in 2003. The mean monthly exposed wetland area has increased by $575 \mathrm{~km}^{2}$ in April while the area has expanded by $1078 \mathrm{~km}^{2}$ in October.

(3) A significant decrease in precipitation has contributed to the EWA increase in April.

(4) The filling of the TGD reservoir has induced incision along the downstream reaches of the Changjiang River and a decrease in discharge in October, increasing the water flow from the lake to the river. We conclude that TGD operation is responsible for the early wetland exposure in October.

\section{Acknowledgements.}

This study was supported by the National Science Foundation of China (NSFC) (41576087, 41361003).

\section{References}

Alexandersson, H., Moberg, A., 1997. Homogenization of Swedish temperature data, Part I: Homogeneity test for linear trends. Int. J. Climatol. 17, 25-34.

Andreoli, R., Yesou, H., Li, J., Desnos, Y., Huang, S., de Fraipont, P., 2007. Poyang Hu (Jiangxi Province, PR of China) area variations between January 2004 and June 2006 using ENVISAT low and medium resolution time series. Geogr. Inf. Sci. 13, 24-35.

Bond, W.K., Cox, K.W., Heberlein, T., Manning, E.W., Witty, D.R., Young, D.A., 1992. Wetland Evaluation Guide: Final report of the wetlands are not wastelands project Sustaining Wetlands Issues Paper 1992-1 North American Wetlands Conservation Council (Canada) Ottawa, Ontario.

Chang, J., Li, J.B., Lu, D., Zhu, X., Lu, C.Z., Zhou, Y.Y., Deng, C.X., 2010. The hydrological effect between Jingjiang River and Dongting Lake during the initial period of Three Gorges Project operation. J. Geogr. Sci. 20(5), 771-786.

Cowardin, L.M., Carter, V., Golet, F.C., LaRoe, E.T., 1979. Classification of wetlands and deepwater habitats of the United States. U.S. Fish and Wildlife Service. FWS/OBS-79/31. Washington, DC.

Dahl, T.E., 2006. Status and trends of wetlands in the conterminous United States 1998 to 2004. U.S. Department of the Interior, Fish and Wildlife Service, Washington, DC, 112pp. 
Dai, Z.J., Chu, A., Stive, M.J.F., Yao, H.Y., 2012. Impact of the Three Gorges Dam overruled by an extreme climate hazard. Nat. Hazards Rev. 13, 310-316.

Dai, Z., Liu, J.T., 2013. Impacts of large dams on downstream fluvial sedimentation: An example of the Three Gorges Dam (TGD) on the Changjiang (Yangtze River). J. Hydrol. 480, 10-18.

Davidson, N.C., 2014. How much wetland has the world lost? Long-term and recent trends in global wetland area. Mar. Freshwater Res. 65, 934-941.

de Leeuw, J., Shankman, D., Wu, G., de Boer, W.F., Burnham, J., He, Q., Yesou, H., Xiao, J., 2010. Strategic assessment of the magnitude and impacts of sand mining in Poyang Lake, China. Reg. Environ. Change 10, 95-102.

Erwin, K.L., 2009. Wetlands and global climate change; the role of wetland restoration in a changing world. Wetl. Ecol. Manag. 17, 71-84.

Feng, L., Hu, C., Chen, X., Zhao, X., 2013. Dramatic inundation changes of China's two largest freshwater lakes linked to the Three Gorges Dam. Environ. Sci. Technol. 47, 9628-9634.

Guo, H., Hu, Q., Zhang, Q., Feng, S., 2012. Effects of the Three Gorges Dam on Yangtze River flow and river interaction with Poyang Lake, China: 2003-2008. J. Hydrol. 416-417, 19-27.

Hao, Y., Liu, G., Li, H., Li, Z., Zhao, J., Yeh, T.J., 2012, Investigation of karstic hydrological processes of Niangziguan Springs (North China) using wavelet analysis. Hydrol. Process. 26, 3062-3069.

Harvey, J.W., Schaffranek, R.W., Noe, G.B., Larsen, L.G., Nowacki, D.J., O’Connor, B.L., 2009. Hydroecological factors governing surface water flow on a low-gradient floodplain. Water Resour. Res. 45, W03421.

Hu, Z.P., Ge, G., Liu, C.L., Chen, F.S., Li, S., 2010. Structure of Poyang Lake wetland plants ecosystem and influence of lake water level for the structure. Resources and Environment in the Yangtze Basin 19(6), 597-605. (In Chinese with English abstract)

Jarusková, D., 1994. Change-point detection in meteorological measurement. Mon. Wea. Rev. 124, 1535-1543.

Kalff, J., 2002. Limnology: Inland Water Ecosystems. Prentice Hall, Upper Saddle River.

Kendall, M.G., 1975. Rank Correlation Methods. 4th Edition, Charles Griffen, London. ISBN: 0195205723.

Klemas, V., 2011. Remote sensing of wetlands: Case studies comparing practical techniques. J. Coastal Res. 27, 418-427.

Lai, X.J., Jiang, J.H., Yang, G.S., Lu, X.X., 2014. Should the Three Gorges Dam be blamed for the extremely low water levels in the middle-lower Yangtze River? Hydrol. Process. 28, 150-160. 
Maltby, E., 1990. Wetland management goals: wise use and conservation. Landscape Urban Plan. 20, 9-18.

Mann, H.B., 1945. Nonparametric test against trend. Econometrica 13, 245-259.

Mei, X., Dai, Z., Du, J., Chen, J., 2015. Linkage between Three Gorges Dam impacts and the dramatic recessions in China's largest freshwater lake, Poyang Lake. Scientific Reports 5, 18197.

Ordoyne, C., Friedl, M.A., 2008. Using MODIS data to characterize seasonal inundation patterns in the Florida Everglades. Remote Sens. Environ. 112, 4107-4119.

Prigent, C., Matthews, E., Aires, F., Rossow, W.B., 2001. Remote sensing of global wetland dynamics with multiple satellite data sets. Geophys. Res. Lett. 28(24), 4631-4634.

Qiu, J., 2011. China admits problems with Three Gorges Dam. Nature News. DOI: 10.1038/news.2011.315.

Sang, H., Zhang, J., Lin, H., Zhai, L., 2014. Multi-Polarization ASAR Backscattering from Herbaceous Wetlands in Poyang Lake Region, China. Remote Sens. 6(5), 4621-4646.

Tan, G.L., Guo, S.L., Wang, J., Lv, S., 2013. Research on the evolution of hydrology and water resources ecological economic zone of Poyang Lake. Beijing: China Water Conservancy and Hydropower Press 130-133 (in Chinese).

Tiner, R.W., 1996. Wetlands. In: Manual of Photographic Interpretation, 2nd edition. Falls Church, Virginia: American Society for Photogrammetry and Remote Sensing, 2440p.

Torrence, C., Compo, G.P., 1998. A practical guide to wavelet analysis. Bull. Amer. Meteor. Soc. 79(1), 61-78.

Töyrä, J., Pietroniro, A., 2005. Towards operational monitoring of a northern wetland using geomatics-based techniques. Remote Sens. Environ. 97, 74-191.

Tullos, D., 2009. Assessing the influence of Environmental Impact Assessments on science and policy: an analysis of the Three Gorges Project. J. Environ. Manage. 90 (3), S208-S223.

Todd, M.J., Muneepeerakul, R., Pumo, D., Azaele, S., Miralles-Wilhelm, F., Rinaldo, A., RodriguezIturbe, I., 2010. Hydrological drivers of wetland vegetation community distribution within everglades National Park, Florida. Adv. Water Resour. 33, 1279-1289.

Wu, G., Liu, Y., 2015. Combining multispectral imagery with in situ topographic data reveals complex water level variation in China's largest freshwater lake. Remote Sens. 7, 13466-13484.

Xie, Y. H., Tang, Y., Chen, X.S., Li, F., Deng, Z.M., 2015. The impact of Three Gorges Dam on the downstream eco-hydrological environment and vegetation distribution of East Dongting Lake. Ecohydrol. 8, 738-746.

Xu, X.H., Lei, S., Wang, X.X., Zhang, Z., 2014. Underwater topography analysis of Poyang Lake by DEM. Yangtze River 45(21), 30-32. (In Chinese with English abstract) 
Ye, X., Zhang, Q., Liu, J., Li, X., Xu, C.Y., 2013. Distinguishing the relative impacts of climate change and human activities on variation of streamflow in the Poyang Lake catchment, China. J. Hydrol. 494, 83-95.

Ye, X., Li, Y., Li, X., Zhang, Q., 2014. Factors influencing water level changes in China's largest freshwater lake, Poyang Lake, in the past 50 years. Water Int. 39(7), 983-999.

Zedler, J.B., Kercher, S., 2005. Wetlands resources: Status, trends, ecosystem services, and restorability. Annu. Rev. Environ. Resour. 30, 39-74.

Zhang, Q., Li, L., Wang, Y.G., Werner, A.D., Xin, P., Jiang, T., Barry, D.A., 2012. Has the Three-Gorges Dam made the Poyang Lake wetlands wetter and drier? Geophys. Res. Lett. 39, L20402.

Zhang, G.Q., Xie, H.J., Yao, T.D., Kang, S.C., 2013. Water balance estimates of ten greatest lakes in China using ICESat and Landsat data. Chinese Sci. Bull. 58, 3815-3829.

Zhang, Q., Ye, X.Y., Werner, A.D., Li, Y.L., Yao, J., Li, X.H., Xu, C.Y., 2014. An investigation of enhanced recessions in Poyang Lake: Comparison of Yangtze River and local catchment impacts. J. Hydrol. 517, 425-434.

Zhu, L., Chen, J., Yuan, J., Dong, B., 2014. Sediment erosion and deposition in two lakes connected with the middle Yangtze River and the impact of Three Gorges Reservoir., Advances in water science 25(3), 348-357. (In Chinese with English abstract) 


\section{Figure captions}

Fig. 1 Map of Poyang Lake catchment in China. a) Poyang Lake's location in relation to the Changjiang River, the Three Gorges Dam and the East China Sea; b) Poyang Lake catchment; c) Poyang Lake bathymetry (referred to the 1985 National Elevation datum); and d) relationship between water level and emergent wetland area (blue circles represent the measured data while the red line denotes the polynomial fitting curve).

Fig. 2 Sketch of Poyang Lake describing the exposed wetland area with respect to a specific water level. a) Average EWA during the dry season with a lake water level of $11 \mathrm{~m}$ (blue zone represents the $11 \mathrm{~m}$ submerged area, while green zone denotes the total lake area); and b) Average EWA during the wet season with a lake water level of $16 \mathrm{~m}$ (blue zone represents the $16 \mathrm{~m}$ submerged area, while green zone denotes the total lake area).

Fig. 3 Average annual water level at the Xingzi station for the period 1960-2010.

Fig. 4 Emergent Wetland Area (EWA) at Poyang Lake for the period 1955-2012. a) monthly EWA; b) decadal averages of monthly EWA; c) annual averaged EWA, the dotted horizontal lines represent the average for the period 1955-2003 and 2003-2012; and d) yearly coefficient of variation for daily EWA, the dotted horizontal lines represent the average for the period 1955-2003 and 2003-2012.

Fig. 5 Wavelet analysis of the monthly emergent wetland area (EWA) from 1955 to 2012. a) normalized monthly EWA; b) filtered monthly EWA; c) normalized wavelet power spectrum compared to global wavelet power spectrum (the blue line is the averaged variance while the red line is the $5 \%$ significant level for the global wavelet spectrum); and d) filtered wavelet power spectrum compared to global wavelet power spectrum.

Fig. 6 Occurrence probability of daily exposed wetland area in each month. Green bars represent the frequency distribution before the construction of the Three Gorges Dam, while yellow bars denote the frequency distribution after the filling of the dam. Solid blue lines are the cumulative frequency distributions in the pre-dam period while the solid red lines are the cumulative frequency distributions in the post-dam period.

Fig. 7 Bottom elevation of Poyang Lake along the central cross-section A-B indicated in Fig. 1b in 1998 (dotted line) and in 2010 (solid line).

Fig. 8 Relationship between monthly rainfall and exposed wetland area from 1956 to 2012, the blue line represents the linear regression.

Fig. 9 Decadal variations of monthly exposed wetland area (EWA) from 1963 to 2012, the red curve denotes the decadal EWA fluctuation pattern in each month.

Fig. 10 Local scar along the Poyang Lake channel created by sand mining (photo taken during low water on 3 Jan., 2015)

\section{Supplementary material}


Fig. S1 Number of reservoirs in the Poyang Lake catchment from 1970 to 2007. 


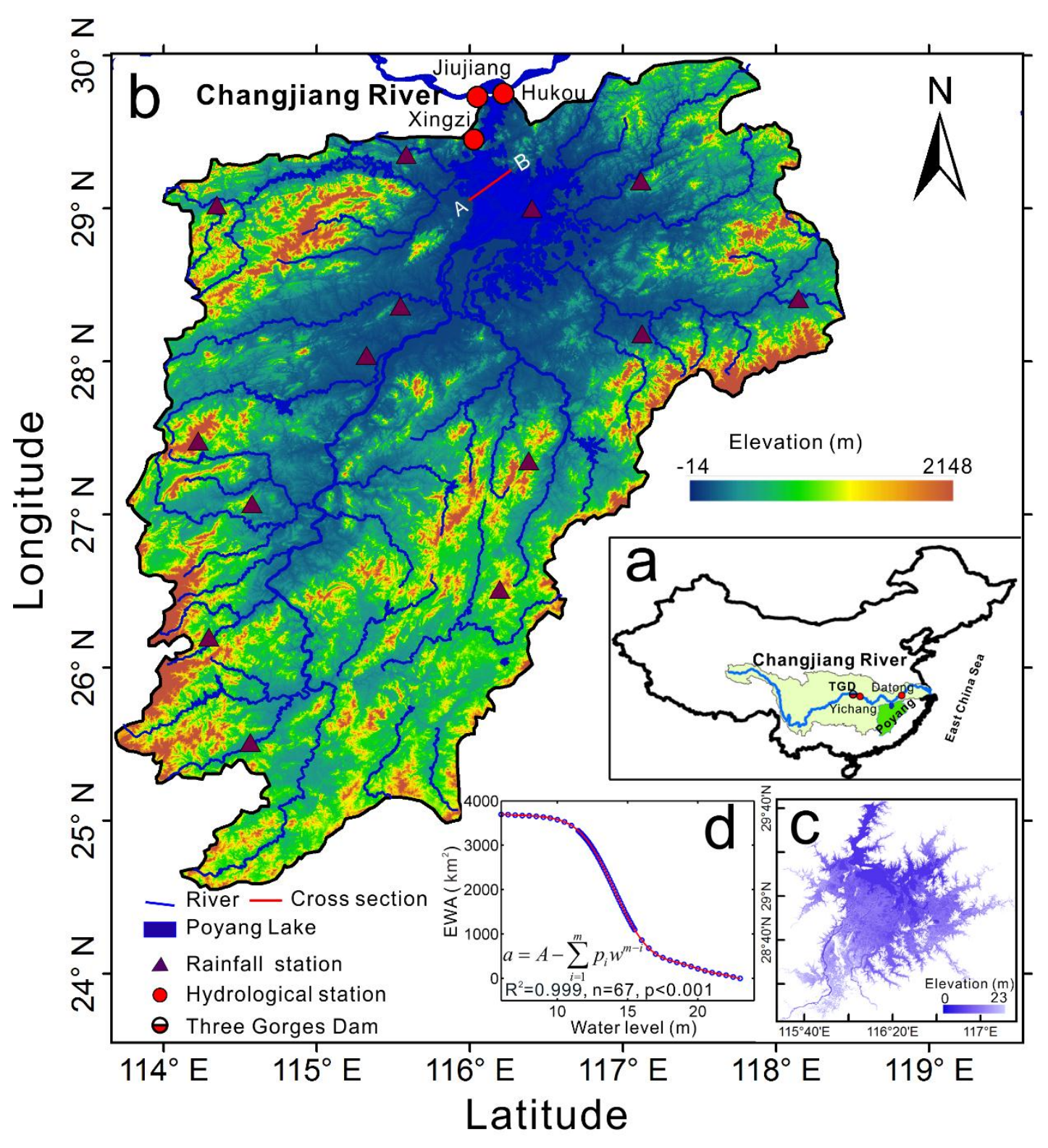



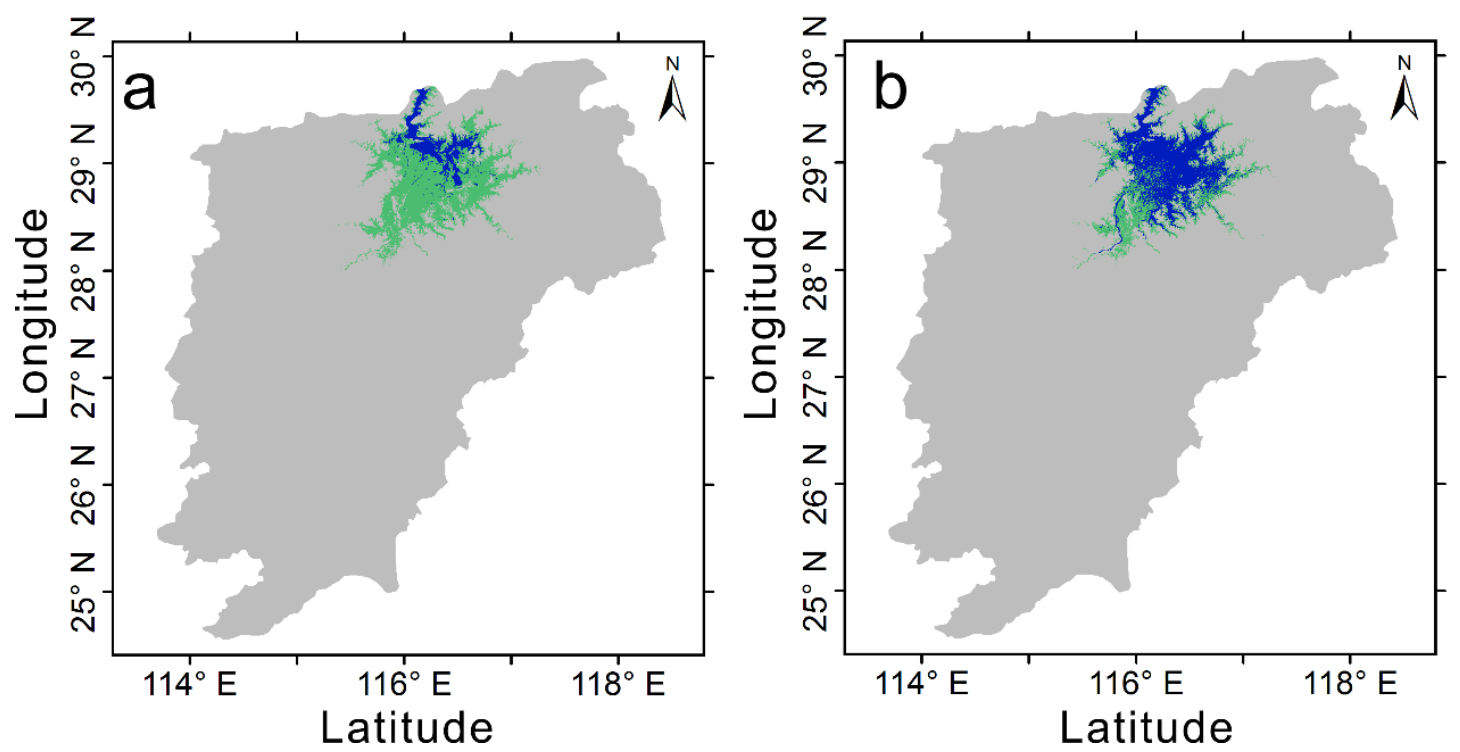


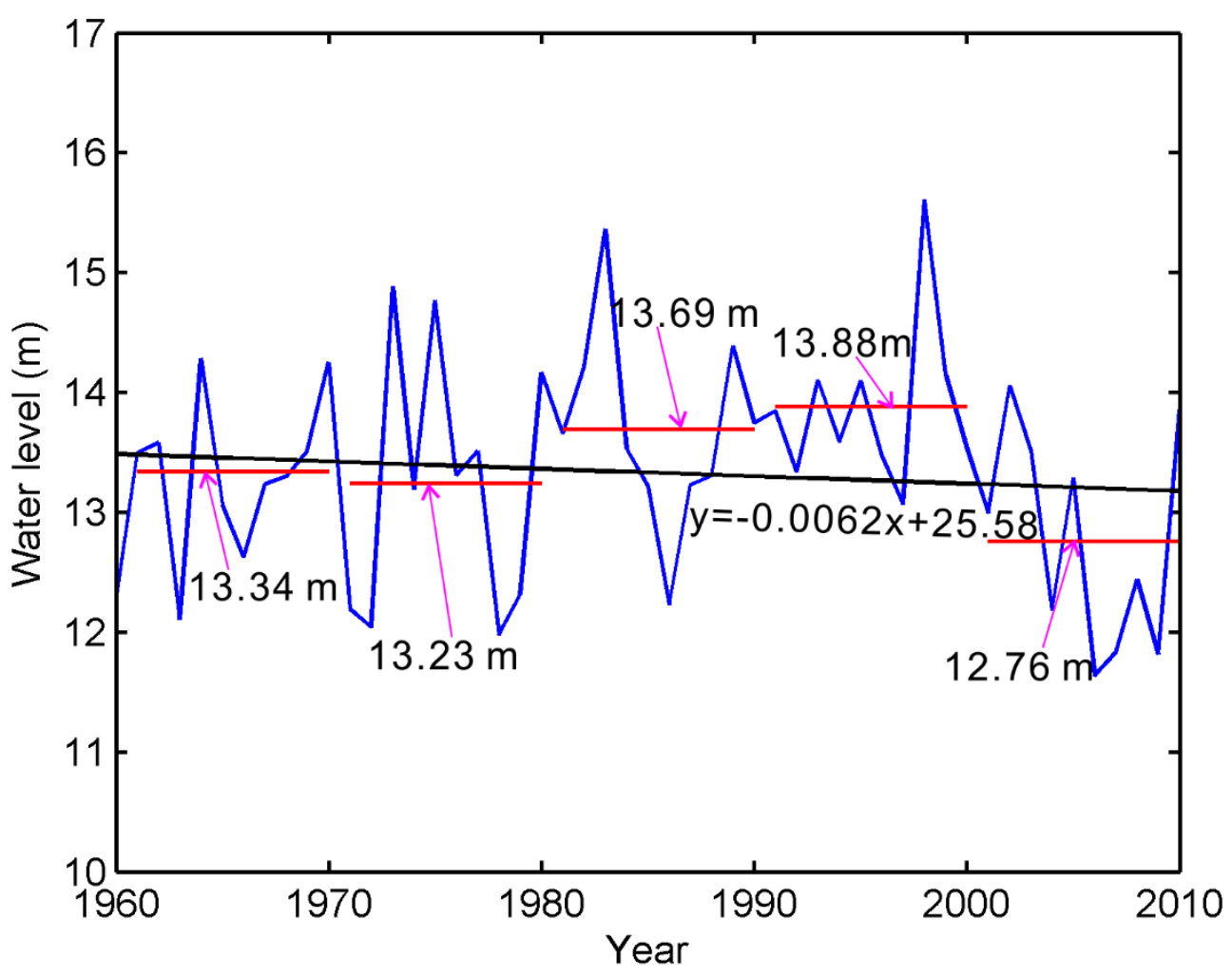



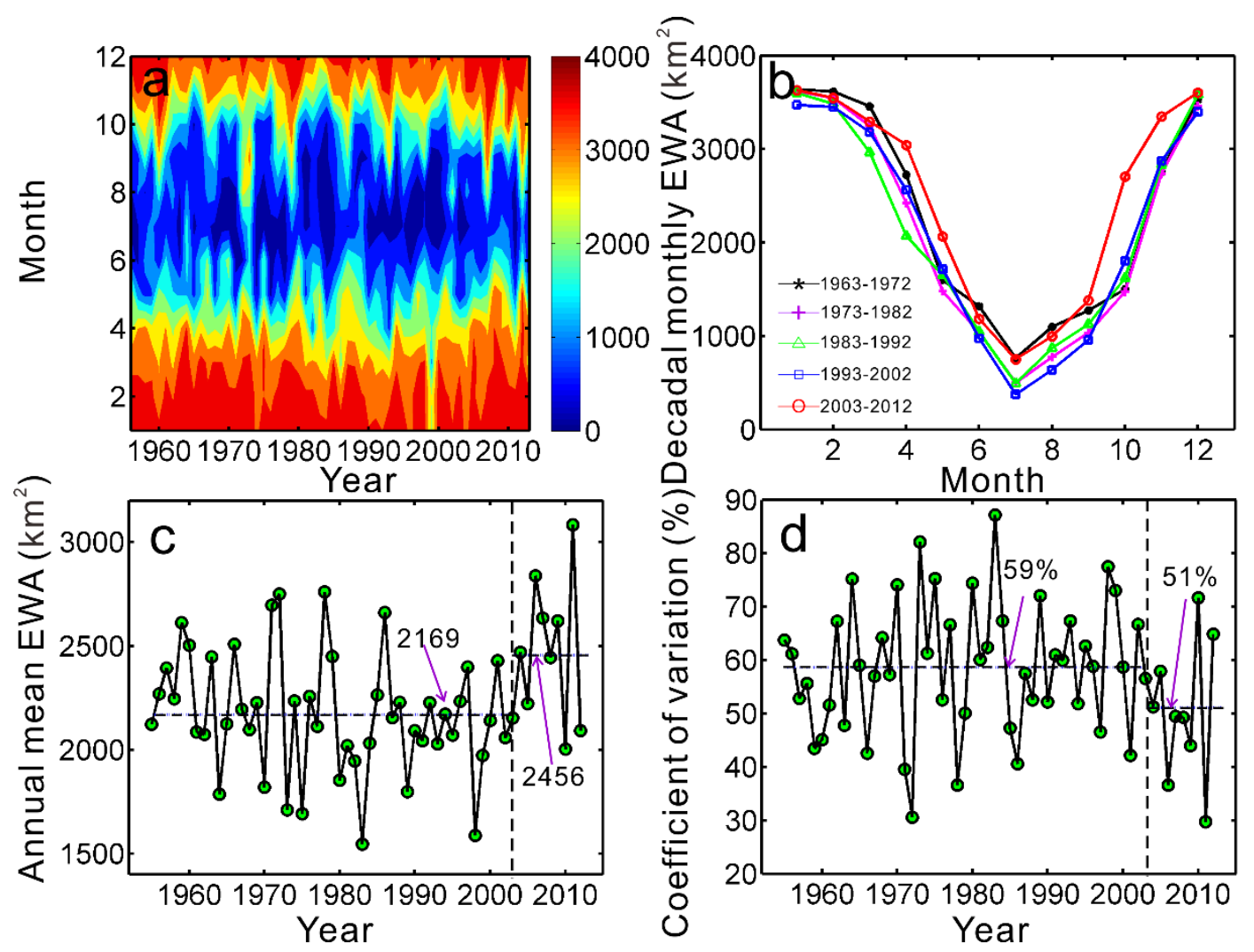

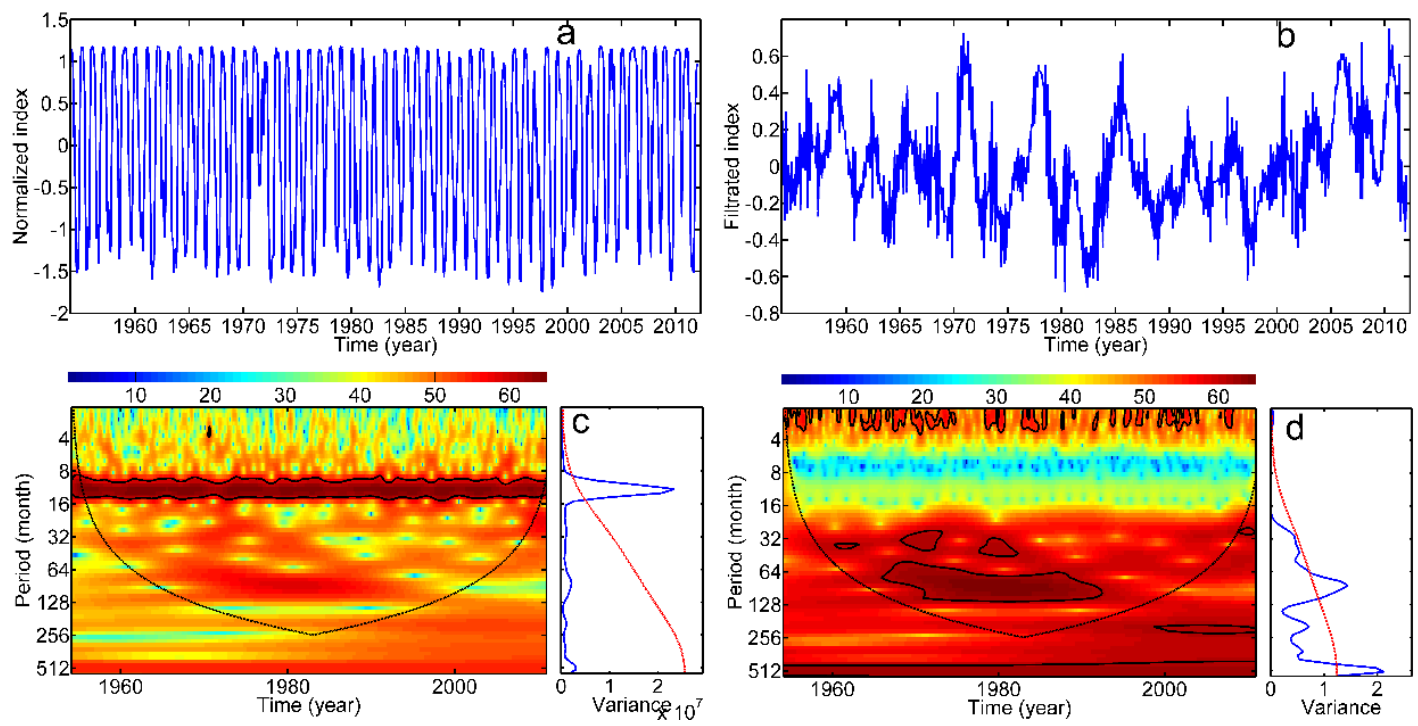

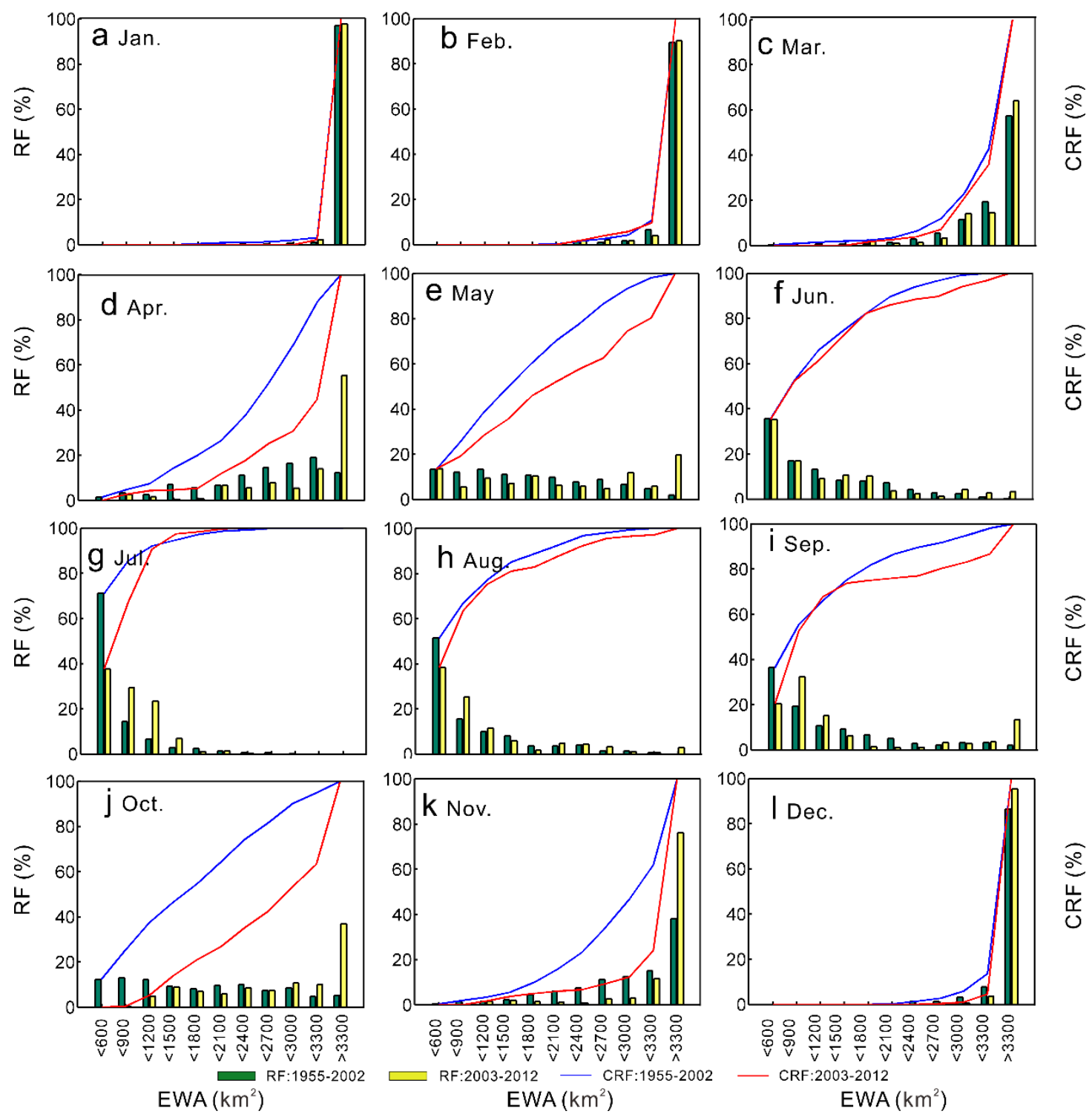

$\square$ RF:2003-2012
EWA $\left(\mathrm{km}^{2}\right)$

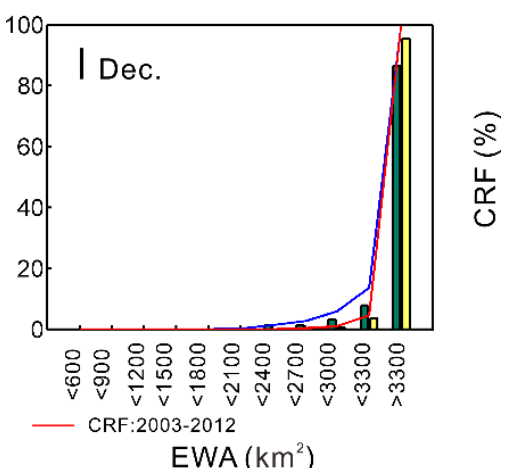




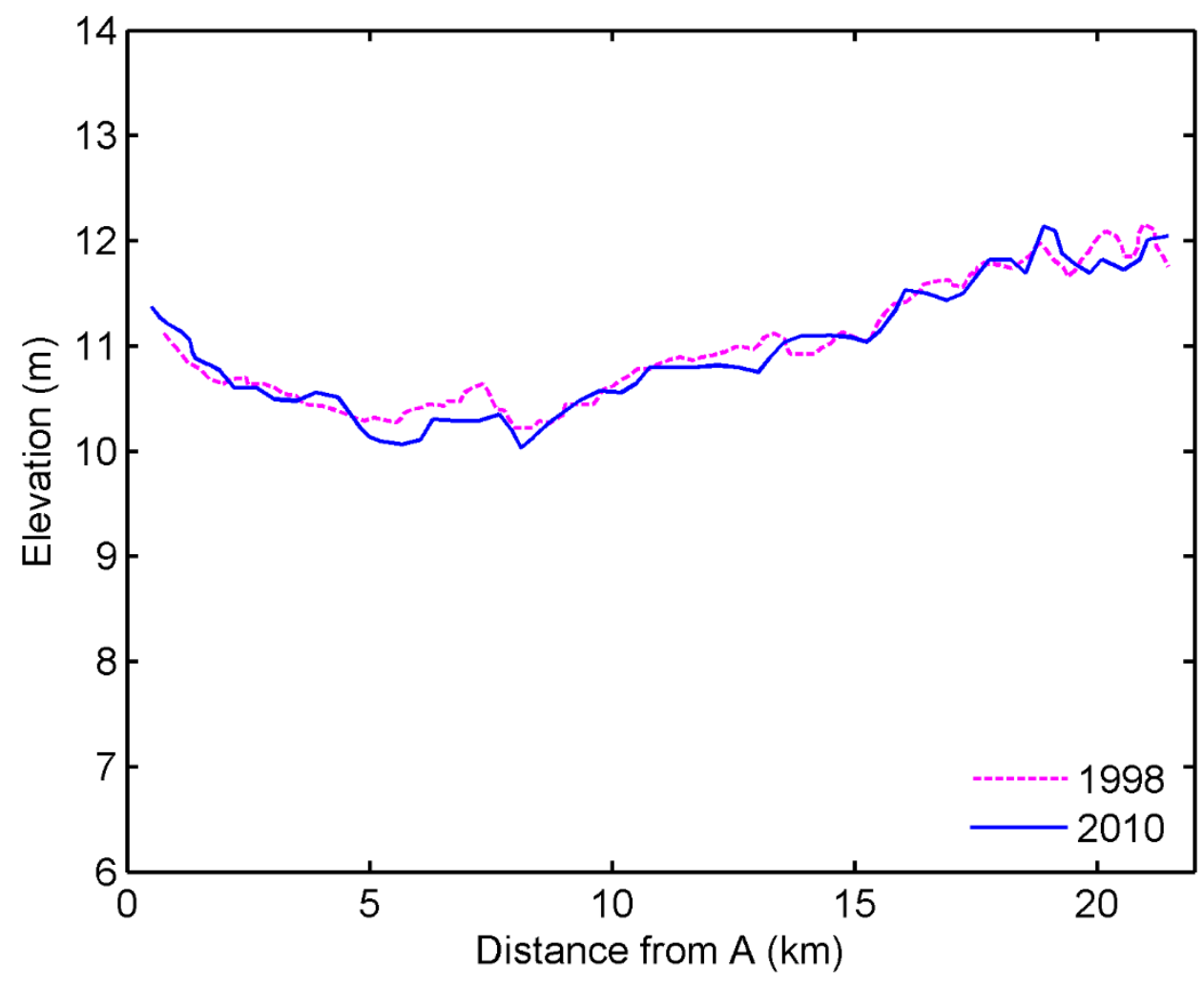




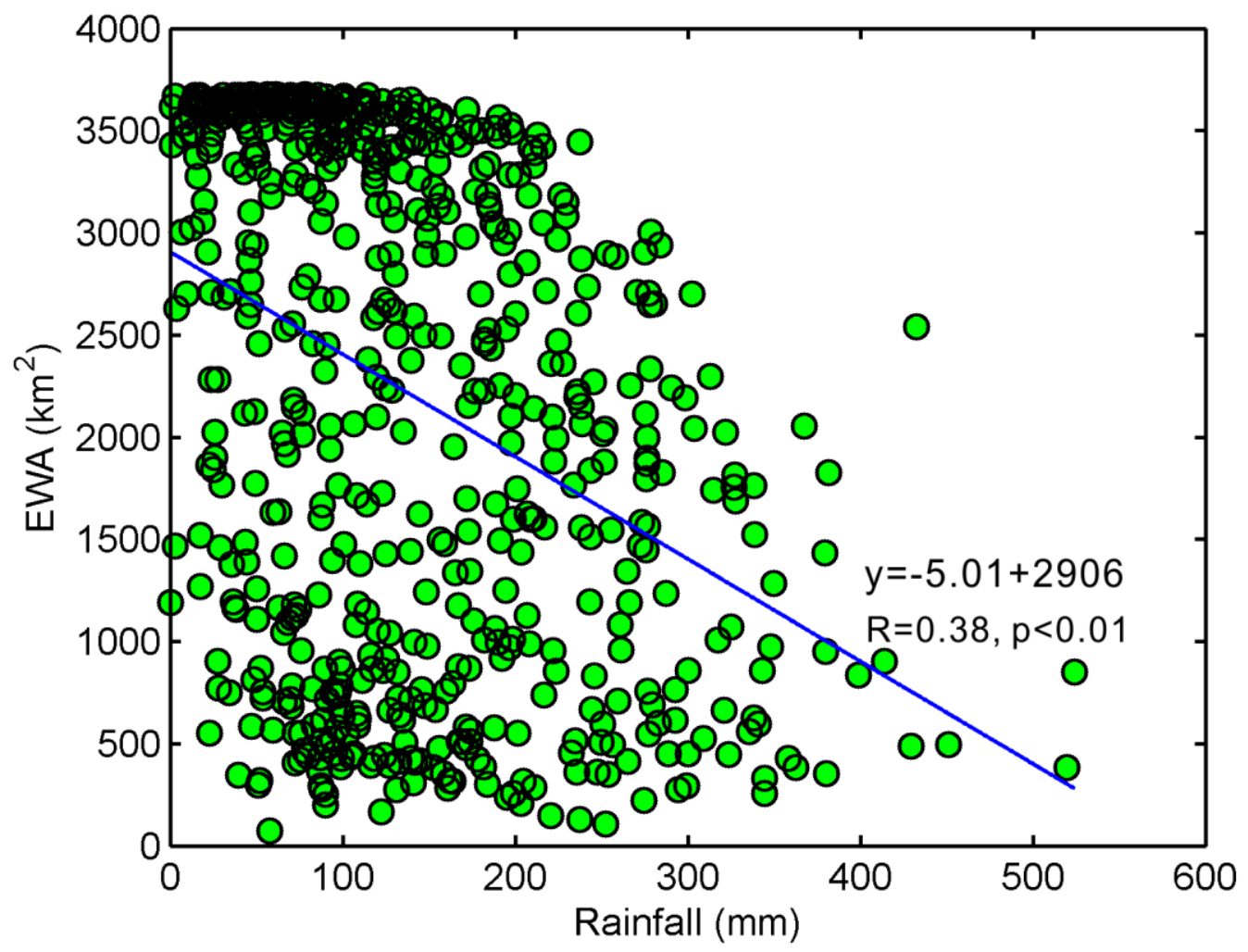




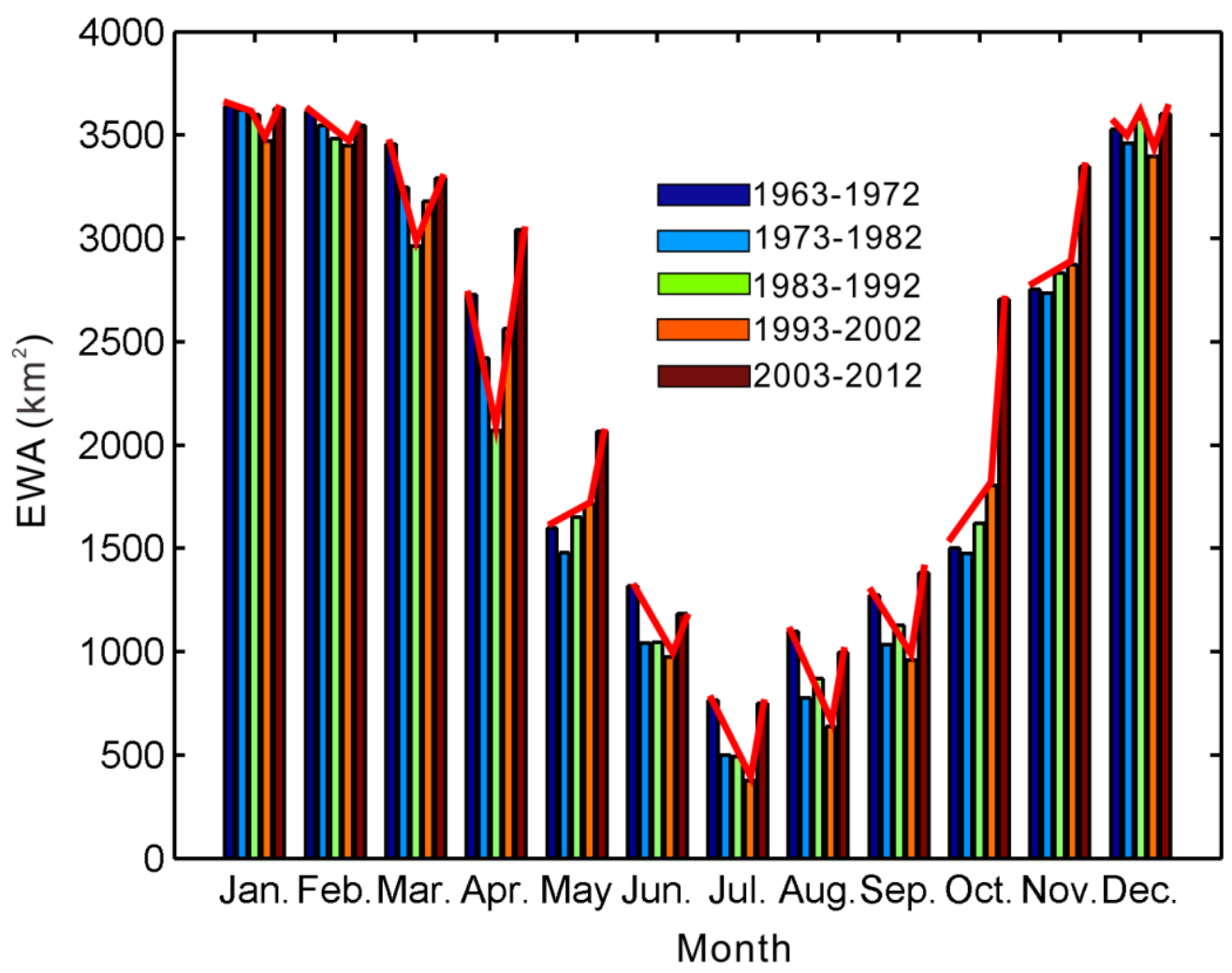




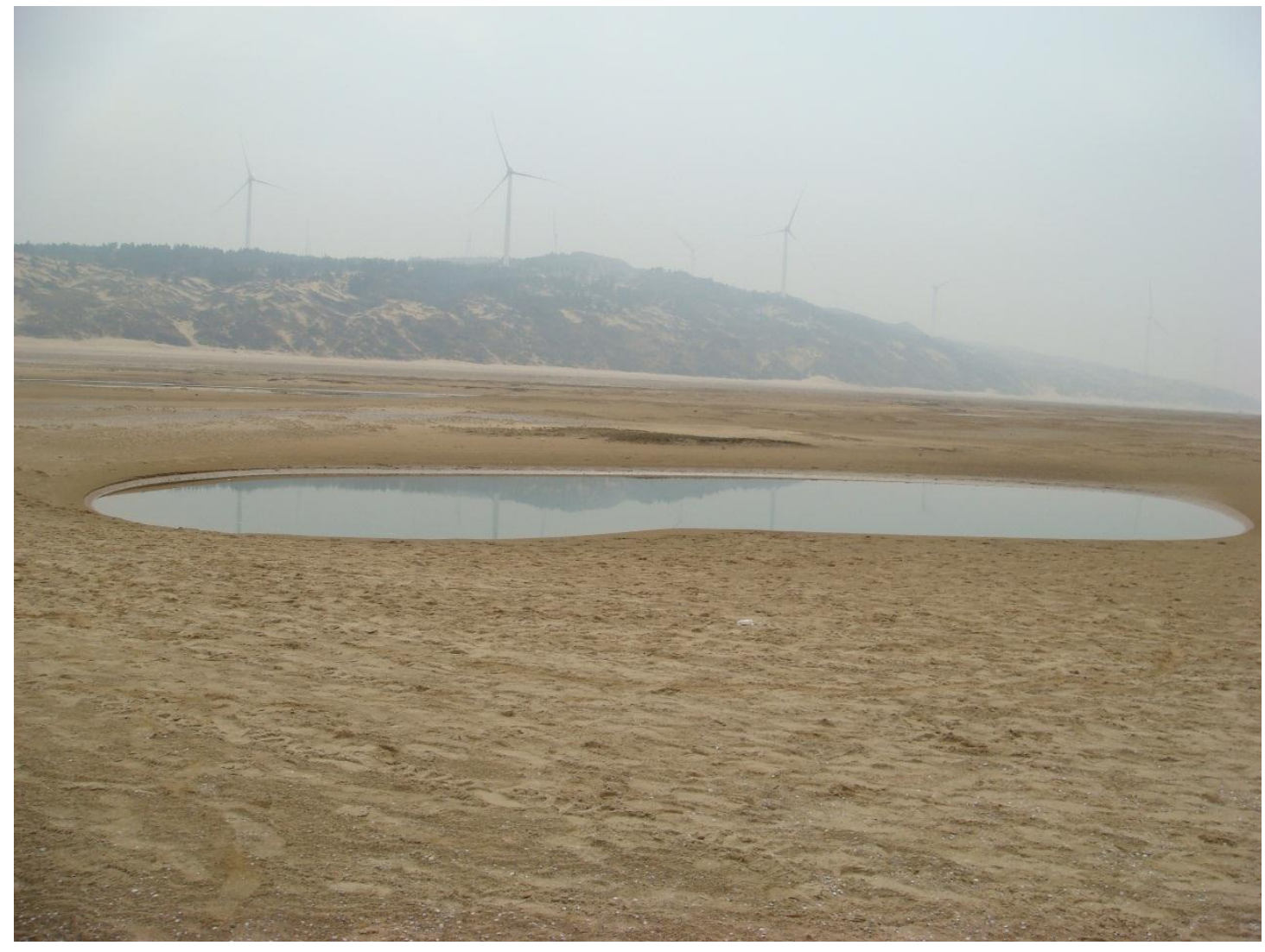



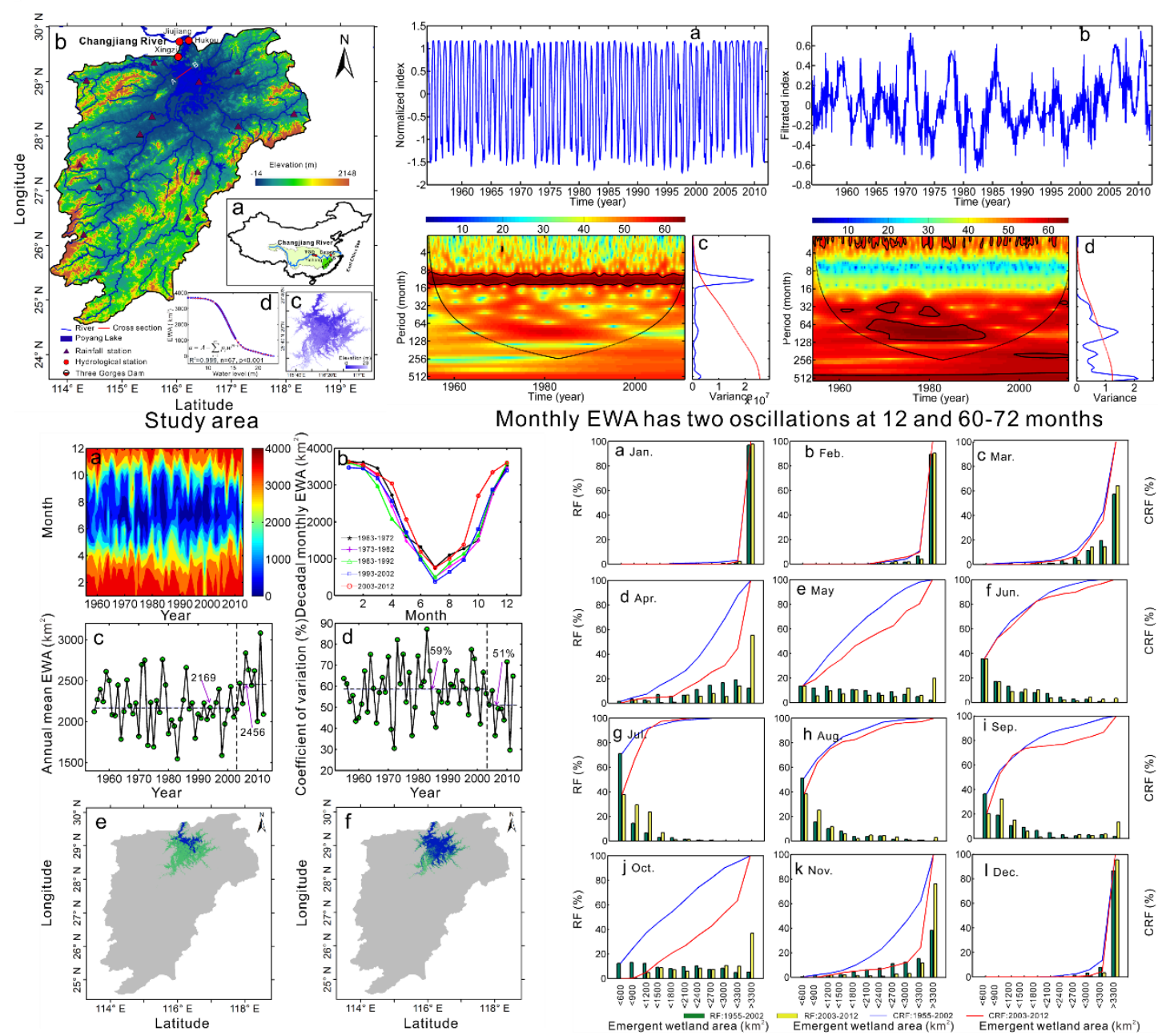

Annual mean EWA increased dramatically since 2003 Seasonal drying of $1078 \mathrm{~km}^{2}$ wetlands occured in Oct.

Timing of wetland emergence in the dry season shifts from November to October 
Table 1. Parameters of the polynomial function for surface area and water level at Xingzi

\begin{tabular}{lllll}
\hline $\mathrm{I}$ & 1 & 2 & 3 & 4 \\
\hline $\mathrm{P}_{\mathrm{i}}$ & $-7.21 \times 10^{-7}$ & $1.13 \times 10^{-4}$ & -0.0079 & 0.3249 \\
$\mathrm{I}$ & 5 & 6 & 7 & 8 \\
$\mathrm{P}_{\mathrm{i}}$ & -8.6525 & 157.12 & -1985 & 17434 \\
$\mathrm{I}$ & 9 & 10 & 11 & 12 \\
$\mathrm{P}_{\mathrm{i}}$ & $-1.04 \times 10^{5}$ & $4.07 \times 10^{5}$ & $-9.26 \times 10^{5}$ & $9.36 \times 10^{5}$ \\
\hline
\end{tabular}


Table 2. Trend analysis of monthly wetland area based on MK and SNHT test

\begin{tabular}{llll}
\hline Month & \multicolumn{2}{l}{ MK test } & SNHT test \\
\cline { 2 - 3 } & $1955-2002$ & $1955-2012$ & 3.26 \\
\hline 1 & -3.05 & -1.57 & 2.98 \\
2 & -1.75 & -0.59 & 5.18 \\
3 & -1.43 & -0.82 & $7.73(2003)$ \\
4 & -1.41 & -0.62 & 4.51 \\
5 & 0.47 & 1.27 & 1.54 \\
6 & 0 & 0.36 & 3.47 \\
7 & -2.11 & -0.4 & 1.08 \\
8 & -1.43 & -0.8 & 2.63 \\
9 & -0.51 & 0.3 & $11.19(2003)$ \\
10 & 0.03 & 2.09 & 5.32 \\
11 & -0.92 & 1.17 & 2.64 \\
12 & -2.04 & -0.52 & \\
\hline
\end{tabular}

Note: The critical value for the MK test is 1.96 with $p<0.05$, while the critical value for SNHT test is dependent on the sample size (Jarusková, 1994). 
Table 3. Comparison of emergent wetland area and precipitation variations between April and October

\begin{tabular}{llllll}
\hline Month & & $\begin{array}{l}\text { Mean EWA } \\
\left(\mathrm{km}^{2}\right)\end{array}$ & \multicolumn{3}{c}{ Precipitation } \\
\cline { 3 - 6 } & & Direct precipitation $(\mathrm{mm})$ & $\begin{array}{l}\text { Tributary } \\
\left.\mathrm{m}^{3}\right)\end{array}$ & inflow $\quad\left(10^{8}\right.$ \\
\hline \multirow{4}{*}{ April } & $1960-2002$ & 2467 & 240.5 & 158.5 & \\
& $2003-2012$ & 3042 & 184.4 & 134.5 & \\
& Difference & 575 & -56.1 & -24.0 & \\
October & $1960-2002$ & 1627 & 62.8 & 45.3 \\
& $2003-2012$ & 2705 & 47.9 & 31.6 & \\
& Difference & 1078 & -14.9 & -13.7 & \\
\hline
\end{tabular}


Table 4. Comparison of Emergent Wetland Area (EWA) in Poyang Lake and discharge in the Changjiang River pre- and post-TGD (averaged value computed in April and October)

\begin{tabular}{lllll}
\hline Month & & EWA & \multicolumn{2}{c}{ Changjiang River discharge } \\
\cline { 4 - 5 } & & $\left(\mathrm{km}^{2}\right)$ & Yichang $\left(\mathrm{m}^{3} / \mathrm{s}\right)$ & Datong $\left(\mathrm{m}^{3} / \mathrm{s}\right)$ \\
\hline April & $1960-2002$ & 2467 & 6690 & 24412 \\
& $2003-2012$ & 3042 & 7027 & 22070 \\
& Variation & 575 & 337 & -2342 \\
October & $1960-2002$ & 1627 & 18182 & 32910 \\
& $2003-2012$ & 2705 & 12268 & 25378 \\
& Variation & 1078 & -5914 & -7532 \\
\hline
\end{tabular}


Table 5. Comparison of EWA variations in Dongting Lake and Poyang Lake during wintertime

\begin{tabular}{llll}
\hline Indices & Period & \multicolumn{1}{c}{$\begin{array}{c}\text { Dongting } \\
\text { (source: Xie et al., 2015) }\end{array}$} & Poyang \\
\hline EWA growth rate & $1995-2003$ & 12.3 & 5.01 \\
$\left(\mathrm{~km}^{2} /\right.$ year) & $2004-2011$ & 14.1 & 9.02 \\
& Variation & 1.8 & 4.01 \\
EWA minimum elevation & $1995-2003$ & 3.1 & 1.78 \\
reduction rate (cm/year) & $2004-2011$ & 7.9 & 3.12 \\
& Variation & 4.8 & 1.34 \\
\hline
\end{tabular}

